\title{
Research on the Influencing Factors of Reverse Innovation of Non - core Enterprises
}

\author{
Guifeng Song \\ International Business School \\ Yunnan University of Finance and Economics \\ Kunming, China \\ 875563127@qq.com
}

Dongping $\mathrm{Yu}^{*}$

International Business School

\author{
Yunnan University of Finance and Economics \\ Kunming, China \\ 247096657@qq.com
}

Xiangxue Lu

International Business School

Yunnan University of Finance and Economics

Kunming, China

1810842206@qq.com

\begin{abstract}
Innovation is the key to maintain core competitiveness for enterprises. In addition, innovation can make non-core enterprise become core enterprise, so it is vital for noncore enterprises and core enterprises. With the development of economic globalization and the deepening of reverse innovation, it is necessary to summarize the influencing factors of reverse innovation of non-core enterprises. On the basis of expounding the concept and characteristics of reverse innovation, this paper summarizes the motivation factors and resistance factors which influence the reverse innovation of non - core enterprises, and prospect the future research which will help non-core enterprises improve core competitiveness through innovation and enter the mainstream market.
\end{abstract}

Keywords-non-core enterprise; reverse innovation; influencing factors; prospect

\section{INTRODUCTION}

The process of economic globalization has accelerated the rise of emerging markets and developing countries, making more and more non-core enterprises set foot on the road to become the core business through independent innovation. Early research on reverse innovation is mainly based on the innovation of enterprises in developed countries, and with the development of economic globalization and the continue rise of emerging markets and developing countries, more and more reverse innovation come from non-core enterprises, such as Haier "Small small prodigy "washing machine, Huawei, BYD company. Non-core enterprises are usually small and medium enterprises (SMEs) in the edge of the industry. In fact, playing an important role in promoting the national economic development, increasing tax revenue, increasing social employment and so on, China's SMEs have experienced an evolution process from small to large, weak to strong. The government increasingly attaches importance to the development of SMEs and have developed a number of policies to create a good external survival and development environment for SMEs, but so far SMEs in China still faces many problems in its development process. These questions include small size, lack of technical investment, the small market, low profitability, shorter life expectancy. It is essential for the development of SMEs and even the national economy how to effectively improve the development and management difficulties of SMEs, enhance their technological innovation capability and make them become the core business through innovation.

Based on the concept of reverse innovation, the concept and characteristics of reverse innovation of non-core enterprises, this paper analyses the influencing factors of reverse innovation of non-core enterprises in innovation network, and summarizes the driving factors and constraints factors of reverse innovation of SMEs, which will provide recommendations for SMEs to improve innovation capability and achieve strategic transformation

\section{LITERATURE REVIEW}

\section{A. The concept of reverse innovation defination}

The concept of reverse innovation was presented by General Electric CEO Immelt [2] and Govindara of Tuck Business School, which described the reverse innovation process through the case of GE's portable imaging instrument developed in China. They think reverse innovation is innovative model that innovation appearance for the first time or the first application in the developing countries and then spread to the developed countries. Zhen [3] think the reverse innovation is the innovative model that big companies, targeting the middle and lower markets of emerging markets, integrate existing advanced technologies to apply innovation, then, with the technical improvements, target the high mainstream market value innovation after the mature of technology or product. The essence of reverse innovation is that under the guidance of market demand, multinational companies and local enterprises in the emerging market make use of new innovative resources, optimize technology, simplify the process, reduce product prices, and then achieve economies of scale, which means value innovation. Shan [4] argues that reverse innovation is the innovation model initiated by multinational companies or local firms in emerging countries, using local innovative resources in emerging markets (such as China and India) to complete innovation in developing countries (or emerging countries) and further spread innovations to the developed countries even the global market.

\footnotetext{
* Corresponding author
} 
The core is the reverse, and the key is the direction of the dissemination of innovation. Humphrey and Schmitz [5] suggest that in the promotion process of enterprise innovation ability, technology organization and the market will subtly change, and successful reverse innovation strategy should be comprehensive, that is a synthesize of technological innovation strategies, market innovation strategies, organizational innovation strategies and so on. CORIS [8] think that the main process completed by the latecomer enterprises is the true sense of the strong reverse innovation.

\section{B. Research on Reverse Innovation influencing factors}

After analysing the case of a latecomer firm in India's communications industry, Ray et al. [6] summarizes the three main factors of reverse innovation are: leadership, vision of senior management and innovative group established based on user's demand for availability, functionality, and operability. Wang et al. [7] pointed out that there are many factors in the success of reverse innovation, and the most important is local innovation resources which usually include the local government's financial support for specific industries, industrial supporting resources and low labour costs and other conditions. Govindarajan and Trimble [9] argue that outdated ways of thinking against reverse innovation, multinationals must take three steps to create a reverse innovative mindset: must shift the company's focus to emerging markets; must accumulate knowledge and expertise in emerging markets; A clear and symbolic act must be taken to change the company's public opinion. Demand differences contribute to reverse innovation, which include performance differences, infrastructure differences, sustainability differences, regulatory differences, and preferences differences. Lim et al. [10] putting Nano car in India's Tata company's as example, expound how the latecomer films continuously improve their technological innovation capability through the reverse innovation strategy.

\section{Research on Reverse Innovation model}

Zhen [3] studied the model of reverse innovation. through the analysis of $\mathrm{R} \& \mathrm{D}$, production and sales process of BYD. She proposed the validity of model which combine making full use of a large number of mature technologies, imitating classic products, process innovation and industrial chain vertical integration. Chinese enterprises can achieve reverse innovation through the "introduction - digestion and absorption -re-innovation". Shan and Dong [11] explores the development model of reverse innovation in Huawei Company from the two dimensions of technology and market and put forward the driving force of reverse innovation in each stage. Especially in the initial stage of reverse innovation, enterprises should target the environmental needs of emerging markets and enhance the ability of technology development and design. Reverse innovation should focus on practicality and seek a balance between cost and performance.

\section{Review of literature}

To sum up, academic study of reverse innovation focused on the following aspects: the definition, influencing factors induction, innovation mode selection, and focus on the case study method. As a new field of research, domestic and foreign scholars' research about reverse innovation is still in its infancy, further research is insufficient. In this paper, the author systematically combed the definition, characteristics and influencing factors of reverse innovation, which would be of great significance for the further study of the reverse innovation of the non-core enterprises.

\section{THE CONNOTATION AND CHARACTERISTICS OF REVERSE INNOVATION OF NON - CORE ENTERPRISES}

\section{A. Connotation of Reverse Innovation of Non - core Enterprises}

The concept of "reverse innovation" was presented by GE's President Jeffery Immelt, T. Tov Business School's V. Govindarajan and Trimble. $\mathrm{C}$ in 2009. The traditional model of innovation is originated in the developed countries. And then introduce innovative results into developing countries. And the reverse innovation model is originated in developing countries. And then spread the results of innovation to other developing countries and even developed countries. In this paper, the reverse innovation is originated from the non-core enterprises. First by the non-core business began to innovate, and gradually become the core business process or phenomenon.

Zhen [3] believes the essence of reverse innovation is under the guidance of market demand, emerging markets, multinational companies and local enterprises to use new innovative resources, optimize technology, simplify the process, reduce product prices, and then achieve economies of scale. The essence is the value innovation. The purpose of reverse innovation is to create value through the large-scale development of emerging markets and low-income market for emerging market customers to find the best solution. The purpose of reverse innovation is to establish a new core competitiveness for enterprises, cultivate new ways of thinking and then put forward to adapt to the development of the times enterprise development strategy.

Non-core enterprise reverse innovation is a spontaneous innovation behaviour. It is based on the characteristics of the local market and continue to carry out the development process of innovation. As a new model of innovation, the independent innovation capability of enterprises could promote the role. Reverse innovation focus on the use of local products to meet the needs of locals, to find the best solution for customers. Non-core enterprises can take advantage of the industry which has not yet developed a mature opportunity to give full play to the advantages of local innovation resources to achieve reverse innovation.

Non-core enterprises have two disadvantages in the market competition. On one hand, non-core enterprises lack the mainstream of the country's technology because of historical reasons. On the other hand, the disadvantages of the market, developing countries lack the mainstream market and the need for mainstream technology customers, so non-core enterprises can only serve the low-end areas of the edge of customers. Non-core enterprises in the industry want to pursue catch-up strategy and have a low-cost competitive advantage. Therefore, non-core companies can take full advantage of their own advantages. Through strategic innovation, it can provide 
consumers with greater value or lower prices for its greater benefits or services obtained relative to the advantages of competitors.

\section{B. The Characteristics of Reverse Innovation of Non-core Enterprises}

The characteristics of reverse innovation of non-core enterprises are mainly reflected in the following aspects: first, reverse innovation originated from non-core enterprises. The general sense of the reverse innovation originated in the core business. The core business compared to non-core enterprises in terms of more innovative and technical supporting. But with the economic development, non-core enterprises gradually rise. In the proportion of the market is getting higher and higher. Secondly, non-core enterprises should be consumer-centric, to determine customer demand, production of simple, powerful, good quality products to meet customer needs. Product production is to meet the market and customer needs. Product performance, functionality in different regions, the customer's needs are not the same. This requires enterprises should to be consumer-centric, product for the region's customer demand for products to meet customer needs. Thirdly, non-core businesses should re-invent products from scratch and start innovating again. At every stage, the market demand for the product is not the same. Companies should be based on demand, re-conceived products, have a new understanding of market demand, reinvent, re-innovation of new products. Fourth, enterprises should be established new core competencies, cultivate new ways of thinking, and build a new global growth platform. Cultivating new ways of thinking is the basis of reverse innovation. Enterprises should play the subjective initiative of people, enhance the sense of innovation, enhance the core competitiveness of enterprises, build a new global growth platform, and on the road to innovation farther and farther.

\section{NON - CORE ENTERPRISES REVERSE INNOVATION DYNAMIC FACTORS}

\section{A. External factors}

\section{1) Government policy support}

The government's policy support plays an important role in the non-core business reverse innovation and enterprise independent innovation ability. In accordance with the spirit of the Third Plenary Session of the Eighteenth Central Committee of the Party, give full play to the decisive role of the market in the process of resource allocation; constantly improve the market mechanism, through the market competition rather than blind policy subsidies and administrative intervention affect the enterprise innovation activities. Zhou [13] that the government's policy support is mainly reflected in the following aspects: first, the government should be a reasonable increase in government innovation fund delivery. The government innovation fund is a government encouraging innovation. It supports high-tech entrepreneurial effective means to become regional innovation level and economic development of the main driving force. Second, the government should continue to strengthen and improve, including property rights system, market-oriented incentive system, sound monetary policy, guaranteed financial payment and other effective policy supply. Third, the government should focus on the economic development of the region to cultivate innovative talents, establish a creative team, and use a good policy environment to attract innovative talents, constantly improve the development of innovative talents mechanism, and strive to maintain the region's economic development the vitality of innovation.

\section{2) Consumer and market demand}

Consumers and market demand is to promote non-core enterprises a major driving force for reverse innovation. In a centain time, consumer demands different products caused by changes in the market. This requires the non-core business to the needs of consumers and the changes in the entire market research. Then enterprises make decisions, re-research and development; redesign the product to meet consumer and market demand. Enterprises should keep an eye on the changes in market development, timely scientific transformation and upgrading, and thus continue to enhance the core competitiveness of enterprises. Yu Feng [12] argues that by relying on the needs of consumers and the market to achieve the purpose of survival and development, and to provide consumers with more satisfied and more fit the needs of consumers products. In the context of rapid socio-economic and technological development, enterprises should make full use of innovative technology to actively develop new products, and then continue to expand the market.

\section{B. Internal factors}

\section{1) The Construction of Enterprise Innovation Culture}

Enterprise innovation culture is not only the core elements of non-core enterprises to achieve innovation and development, but also an important driving force for enterprise innovation work. Enterprise innovation culture can guide the majority of workers to learn common values and pursue common values. Enterprise innovation culture can be used as a kind of appeal to the enterprise workers to guide the enterprise goals. This culture guide enterprise employees continue to achieve the goal of the enterprise and work in long-term. Enterprise innovation culture is a subtle way to communicate with the ideas of enterprise employees. Enterprise workers in a unified ideological guidance and the role of corporate atmosphere, through active innovation, they can result in their work "pride" and business "sense of belonging". Therefore, the enterprise managers should attach great importance to the importance of enterprise innovation culture in the process of enterprise innovation, combine with the actual situation and direction of the enterprise's own development, establish a kind of innovative ideas which conform to the whole innovation of enterprise development, guide enterprises grassroots workers to seriously study and understand this value concept, establish the correct ideological values and cultivate all employees to establish a positive attitude towards the work

2) With the development and innovation of the spirit of the leaders, technical staff

Leaders as the unit and the enterprise managers and organizers, directly affect the enterprise and enterprise employees' awareness of innovation and innovation. Therefore, managers should be fully aware of their important role in the 
organization or business, adapt the needs of economic development, enhance the sense of innovation and strive to improve their ability to innovate. Leaders should have a solid basic theoretical knowledge and scientific and cultural knowledge, learn to look at the world, analyse the development of the times changes, grasp the trend of development of the times and with innovation to lead the development of enterprises. Technical staffs not only have the spirit of innovation for the developments of enterprises but also have a positive role in promoting. Technical staff should have the ability to innovate. Technical staff should be aware of their important role in the enterprise. This requires employees to give full play to their own sense of innovation, strive to learn the relevant basic theoretical knowledge, to overcome the limitations of the relevant research areas and the courage to break through. Managers should encourage technical staff to take full advantage of the initiative, encourage technical staff to actively cultivate the sense of innovation and regular training of technical staff, so that the technical staff innovation to meet the enterprise innovation.

3) The establishment of a modern technology and Chinese characteristics of the enterprise management model

In the management model, non-core enterprises are difficult to compare with the core business. But it's human, material and financial resources, or information, production and distribution channels channels and other key factors in innovation management, as well as business management decision-making, planning, revision and other management links, the same need to give a scientific management organization and cooperation in the operation. With the continuous expansion of business model, non-core enterprise management model should focus on the transition from entrepreneurial management to professional manager management. non-core enterprise management model should from the traditional single enterprise management mode to the group management mode, especially for the implementation of the parent company management model. Li Xiaofang argues that non-core companies should also innovate their management mechanisms through streamlined and fast business processes and establish holistic process organization, quality control and rapid response mechanisms based on business development needs to continuously improve their competitive advantage of products and services, so that the implementation of innovative management measures to a comprehensive and flexible to meet the development needs of different stages of the market.

\section{NON - CORE ENTERPRISE REVERSE INNOVATION RESTRICTIVE FACTORS}

\section{A. Enterprise innovation consciousness is not strong}

Nowadays, innovation is undoubtedly the most popular topic. In the ever-changing economic and social development wave, some people say that business is not innovative. It is tantamount to death. But some people say that enterprises take the initiative to engage in innovation. It is tantamount to court death. But for many small and medium enterprises, through technological innovation and achieve bigger and stronger that is undoubtedly an important way. At present, many small and medium-sized enterprise management level is still relatively low. Family type and family manager exist in large numbrs. These enterprises have a weak sense of innovation and a weak awareness of intellectual property protection, resulting in some independent innovation results by others copy and steal. Many small and medium-sized enterprises in the real interests of the conditions, do not want to invest in independent innovation. There are re-introduction, light digestion, heavy imitation, light innovation phenomenon, the lack of sustained development momentum.

\section{B. Innovation and regulatory system is not perfect}

In China, the relevant laws and regulations for innovation are not systematic enough and lack of integrity. For the entire innovation of the development system, the relevant provisions are too general. There is no specific industry and the specific context of the technical requirements of the method. The relevant laws and regulations are not comprehensive enough. Many regulations and regulations are in the meaning of the same phenomenon, repeating too much and no practical significance. In the labor, tax, management mechanism of the regulations are contradictory. Zhang Dan [14] argues that the Development and Reform Commission and the regional development zone is not real-time communication, for the same issue at the same time promulgated real-time different laws and regulations, resulting in constraints of the disorder. Even to the government departments of openness, transparency and credibility have a great impact.

\section{Financing channels are limited}

At present, the financing difficulties also restrict the innovation investment of SMEs. Most of the small and medium enterprises have shortages of funds.Financing channels are relatively simple. But, because innovative SMEs usually lack of collateral, while banks to small and medium enterprises of the loan interest rates are generally higher than the large enterprises. This exacerbated the small microenterprise financing costs, limited investment in technological innovation. Financing is difficult; financing is still the bottleneck restricting small and medium enterprises. On the whole, there are more indirect methods to guide banks to support small business financing. Indirect methods include loan differentiation regulation, improving the tolerance of non-performing loans and strengthen credit and so on. Incentive effect is limited and support small micro-enterprise financing direct measures less.

\section{Lack of basic conditions and incentives to attract talent}

At present, small and medium enterprises generally lack the basic conditions and incentives to attract talent. Most small and medium enterprises prefer to be able to hire a mature technical staff. They do not want to hire the people need retraining. It causes a young utility technician to have a fault. At the same time, enterprises lack scientific and rational distribution mechanism and incentive mechanism. The ability of scientific and technological staffs has not been effectively 
valued. They are dissatisfied with the proceeds of labour. These three aspects are the main cause of brain drain.
Based on the above analysis, We can build the influence factors system, as shown in Table 1.

TABLE I. THE INFLUENCE FACTORS SYSTEM OF REVERSE INNOVATION FOR NON - CORE ENTERPRISE

\begin{tabular}{|c|c|c|}
\hline \multirow{5}{*}{$\begin{array}{l}\text { Driving } \\
\text { factor }\end{array}$} & \multirow{2}{*}{$\begin{array}{l}\text { external } \\
\text { factors }\end{array}$} & Government policy support \\
\hline & & Consumer and market demand \\
\hline & \multirow{3}{*}{$\begin{array}{l}\text { Internal } \\
\text { factors }\end{array}$} & The Construction of Enterprise Innovation Culture \\
\hline & & With the development and innovation of the spirit of the leaders, technical staff \\
\hline & & $\begin{array}{l}\text { The establishment of a modern technology and Chinese characteristics of the enterprise } \\
\text { management model }\end{array}$ \\
\hline \multirow{4}{*}{\multicolumn{2}{|c|}{ Restrictive Factors }} & Enterprise innovation consciousness is not strong \\
\hline & & Innovation and regulatory system is not perfect \\
\hline & & Financing channels are limited \\
\hline & & Lack of basic conditions and incentives to attract talent \\
\hline
\end{tabular}

\section{CONCLUSIONS AND OUTLOOK}

\section{A. Conclusion}

The reverse innovation strategy is one of the effective ways to construct the independent innovation ability of the non-core enterprises. It is one of the driving forces of the noncore enterprises to gradually move towards the core enterprises. Through the summary of the factors that affect the reverse innovation of non-core enterprises, it allows non-core enterprises to fully understand the direction that needs to be improved. It can make up for their own shortcomings and accelerate the pace of independent innovation. First, in the context of economic globalization, we should be as fast as possible to grasp the needs of consumers and the market to stimulate enterprises. We should continue to use more innovative technology to develop and innovate new products to expand the market. Second, in the composition of enterprise innovation culture, leaders as the enterprise leaders, organizers and managers, should give full play to the positive role in business innovation. They should give a lot of technical personnel to play the space of innovation. As much as possible to give financial support, let them learn to look at the world. Moreover, the leaders should establish a business management model with modern technology and Chinese characteristics. Continuously improve the quality of products, performance to adapt to a variety of market environment and provide the core competitiveness of enterprises. Third, the technical staff is the core of enterprise innovation. They should strive to improve the sense of innovation, overcome the limitations of research areas and the courage to break through their own. Fourth, in terms of corporate innovation constraints, the enterprise should take the initiative to overcome. The government should increase the enterprise innovation funds, policy support. These factors can accelerate the development of regional economy.

\section{B. Outlook}

In summary, at present, the research on the reverse innovation of non-core enterprises still stays in the stage of theoretical exploration. The main research direction in this field will be the mechanism and the realization path of the influencing factors of non-core enterprises. To establish a complete theoretical analysis framework and system approach. The principle of reverse innovation is explored by combining theory with systematic approach. To promote reverse innovation towards deeper, more detailed directions.

\section{ACKNOWLEDGMENT}

This work was supported by Key Programs of Education Department in Yunnan Province (the project number is 2013Z067), supported by Scientific Research Start-up Foundation for Talent Introduction of Yunnan University of Finance and Economics (the project number is YC2013D26), supported by Philosophy and Social Science Planning Program in Yunnan province, (the project number is YB2016064), and supported by Graduate Innovation Fund Project of Yunnan University of Finance and Economics (the project number is 2017YUFEYC020). Thanks for all the sponsors.

\section{REFERENCES}

[1] J. Mathews, "Competitive advantages of the latecomer firm: A resource-based account of industrial catch-up strategies," AsiaPacific Journal of Management, 4th ed, vol. 19, 2002, pp. 467-488.

[2] R. Jeffery, Immelt, G. Vijay, and T. Chis, "How GE is disrupting itself," Harvard Business Review, vol. 10, 2009, pp. 56-65. 
[3] W.L. Zhen, "Reverse innovation model research - Byd company, for example," Scientific and technological progress and countermeasures, 5th ed, vol. 29, 2012, pp. 18-22.

[4] J. Shan, Y. Cheng, and Q.Q. Li, "Reverse innovation research context and future prospect," Scientific and technological progress and countermeasures, 2014, pp. 6-10.

[5] J. Humphrey, and H. Schmitz, "How does insertion in global value chains affect upgrading in industrial clusters," Regional Studies, vol. 9, 2002, pp. 1017-1027.

[6] P.K. Ray, and S. Ray, "Resource-constrained innovation for emerging economies: the case of the Indian telecommunications industry," IEEE Transactions on Engineering Management, 1st ed, vol. 57, 2011,pp. 144156.

[7] J. Wang, L. Xue, and Z. Liang, "Multinational R\&D in China: from home-country-based to host-country-based," Innovation: Management, Policy\&Practice, 2nd ed, vol. 14, 2012, pp. 192-202.

[8] S. Corsi, "Reversing the International Flow of Innovation: How Does Chinese Market Trigger Reverse Innovation?" Pisa: Scuola Superiore Sant' Annadi Studi Universitarie di Peterfezionamento, 2012.
[9] G. Vijay, and T. Chris, "Reverse Innovation: Create Far From Home, Win Everywhere," Harvard Business Review Press, 2012.

[10] C. Lim, S. Han, and H. Ito, "Capability building through innovation for unserved lower end mega markets," Technovation, 33th ed, 2013, pp. 391-404 .

[11] J. Shan, and G.W. Dong, "The reverse innovation path study of emerging market companies - the case study from huawei," Scientific and technological progress and countermeasures, 2nd ed, 2017, pp. 8793.

[12] F. Yu, "Enterprise innovation management key factors," Enterprise strategy, 883th ed, vol. 16, ,2016, pp. 160-162.

[13] C.L. Zhou, and Z.Y. Zhang, "The investigation and analysis of policy factors impact on enterprise innovation," Technology economy and management research, 8th ed, 2016, pp. 40-44.

[14] D. Zhang, "Research in the impacting factors of small and medium-sized enterprise technology innovation," Journal of liaoning university oftechnology, vol. 18, 2016, pp. 24-25. 